\title{
HEALTHCARE SYSTEM FINANCING AND PROFITS: ALL THAT GLITTERS IS NOT GOLD
}

\author{
Tomáš Zelený1, ${ }^{2}$, Vladimír Bencko ${ }^{1}$ \\ 'Institute of Hygiene and Epidemiology, 1st Faculty of Medicine, Charles University, Prague, Czech Republic \\ ${ }^{2}$ Institute of Economic Studies, Charles University, Prague, Czech Republic
}

\begin{abstract}
SUMMARY
The objective of this paper is an analysis of two main attributes of healthcare systems. First of the main attributes is the trend of ever growing expenditures of healthcare systems all across the world. Second attribute is the efficiency of chosen mixed healthcare systems, where mixed system is one which features involvement of both private and public sector. Countries chosen for analysis are USA as the country with high private sector influence on healthcare, France with its mediocre influence and Japan, where the private companies participate in health care but are very strictly regulated by a zero profit rule, and the Czech Republic, where public sector dominates the health care. The result is that the systems with higher influence of the private sector tend to have lesser occupancy, not significantly better performance and higher expenditures. This raise doubts whether the private sector brings anything of value for the patients within the healthcare system. However, more detailed analysis should be carried out to confirm or refuse this hypothesis.
\end{abstract}

Key words: healthcare financing, public and private sectors, long term perspective analysis, cross country comparison

Address for correspondence: T. Zelený, Polní 353/21, 46006 Liberec 12, Czech Republic. E-mail: zeleny.@gmail.com

\section{INTRODUCTION}

This paper consists of two parts. The first part is an analysis of the basic problems of healthcare system, the second part analyses the systems of selected countries - USA, Japan, France, and the Czech Republic with emphasis on the combination of private and public sector in the context of total expenditures for given systems. Ahead of the actual analysis of individual countries, it is crucial to describe and analyse the long term trends in health care expenditures. This trend is a never ending growth, in majority of cases significantly higher than inflation. Trend of health care expenditures per capita is summarized in Figure 1 (1).

\section{Basic Factors of Expenditure Growth}

Particular factors associated with expenditures in healthcare systems can be found in limitless supply, which is the result of

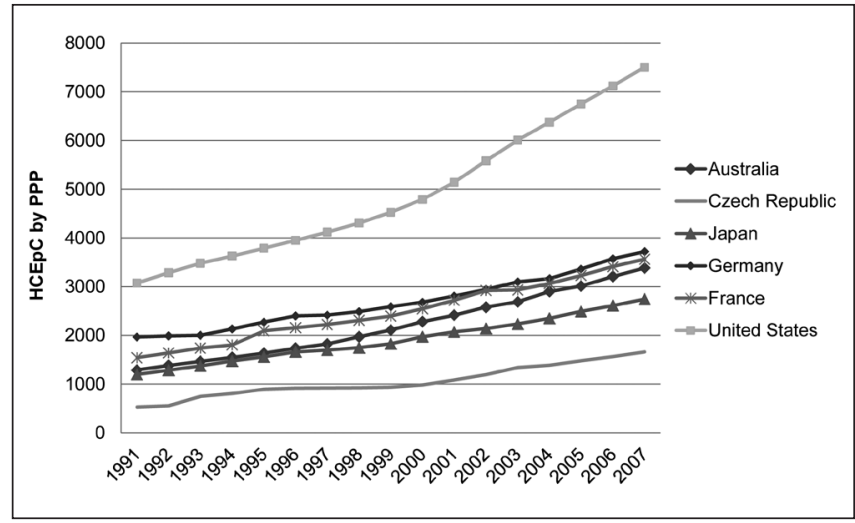

Fig. 1. Health care expenditure per capita by purchasing power parity (PPP) for years 1991-2007. either the currently used system or angle of view of the evaluator. However, there are multiple factors found in systems of most developed world countries (2), from these frequently observed factors we draw the basic factors of healthcare systems. On these factors we construct our analysis, since they are common to most systems and thus provide a good insight into given systems.

Most of these factors are associated with health care demand. There are three key factors - insurance effect, aging of population and growth of average income (3). Aging of population is frequently viewed as an absolutely basic reason why the health care expenditures grow. The vulnerability to health problems is increasing proportionately with the age of a given person. For illustration, we add concrete data from USA for the year 2004 (4).

Existence of insurance also brings another factor, which is labelled as moral hazard - when a patient is insured, he does not carry the financial consequences of his health problems as they are paid by a third party, in this case the insurer, and therefore the patient does not need to include financial costs into his reasoning when treatment is being decided but only treatment effectiveness (5). Should he be given a choice, it would inevitably fall on the best and therefore most expensive available care without looking at any alternatives. In this case, it does not matter whether the insurer is a state or a private subject.

Finally, there is an increase in income. With increasing disposable income increases the amount of resources for a patient to pay

Table 1. Distribution of expenditure across age groups

\begin{tabular}{|l|c|c|}
\hline Age group & $\begin{array}{c}\text { Percentage of total } \\
\text { expenditure }\end{array}$ & $\begin{array}{c}\text { Expenditure per } \\
\text { capita in dollars }\end{array}$ \\
\hline $0-18$ & $13.30 \%$ & 2,650 \\
\hline $19-64$ & $52.50 \%$ & 4,511 \\
\hline $65+$ & $34.30 \%$ & 14,797 \\
\hline
\end{tabular}


for health care. That leads to a vicious circle: people earn more money - spend more money for health care - stay healthier - keep being more productive - earn more money. This is a positive type of a vicious circle which drives the demand for health care - as the demand increases the supply adjusts.

From basic nature of these factors, it is clear to see that the increase of health care expenditures neither happens by itself nor is intrinsically negative - it is a phenomenon, which needs to be accounted for in the future and it cannot be removed. Key question therefore becomes how to arrange the financing system. That way we get to the main topic of this paper-combination of private and public healthcare sectors.

\section{Combined System}

The main property of the combined system is that there are two players in the field - private and public sector. The sectors split the health care among each other by pre-set rules, while the particular division depends on the settings which are unique to each country. This paper examines four examples of such systems - system of USA, Japan, France and the Czech Republic. Country selection was based on the inherent diversity of the healthcare system financing, in particular in relation to the role of private sector. The United States represent a system with the highest share of private sector in health care, where its significant role persists from the former fully free market system from the beginning of the 20th century. France represents a truly mixed system, where both public and private sector have played significant roles and the patients financially participate on health care. The Czech Republic is somewhere around the middle of the spectrum, as on one hand the health care is based on the maximum-supply for free idea, yet patient's financial participation is still present and private sector institutions participate in the system through supplying services, which are not available in the public sector. Finally, Japan represents the fully state directed healthcare system, where the private sector abides strictly defined rules. This chapter is separated into two parts - in the first part we describe the structures of these systems separately, in the second we provide a short statistical analysis of their properties and performance.

\section{USA}

The full impact of the recent US health care reform has yet to be shown and therefore, we focus on the system which was in place before the recent reform efforts. Everything listed holds true for the former system. In USA, the healthcare system comes from its foundations in free market principles. Citizens pay insurance to private insurance companies, those who do not $(15.4 \%$ of the population) pay from their own pockets (6). Those, who would not have sufficient resources can apply for public systems Medicaid and Medicare. Theoretically, Medicaid pays for health care of the poor and Medicare for the pensioners. In practice, however, Medicaid covers only about $40 \%$ of low-income populations, remaining $60 \%$ are excluded from the system through various criteria (7). This determines the source of the problem. Because the American system of health care rose from the free market, it is subject to the market mechanisms - competition and profit maximization. Client, who with high probability is unable to pay for health services is everything but profitable for the insurance company. In the same line of reasoning, client who has a high risk of contracting a high-cost-of-cure disease is not very profitable.

In order to generate profit, it is necessary for the insurance company to select these clients and exclude them from insurance. That unavoidably leads to the fact that the insurance companies use, in contrast to other systems, much more resources for their maintenance. According to WHO, it is common for healthcare institutions to use about $4 \%$ of the total budget for their own maintenance, whilst in USA the insurance companies use about $15 \%$. They employ about 2 million employees, who are responsible only for exclusion of people from the health care and control of the accounts of hospitals, creating obstacles in the payment for health services (8). Cost minimization is, after all, a necessary condition for profit maximization so not insuring people with higher risk of future health problems is axiomatic for insurance companies. Competition is tough - if an insurance company accept high risk clients, costs increase, company have to increase prices or suffer financial loss. With increase of prices the lower risk patients would leave for other companies (not accepting the higher risk patients), which leaves the original company only with high risk patients and heading for a swift bankruptcy.

Market system has also multiple side effects. Apart from uninsured people, there is a significant amount of underinsured people. Those are people with insurance not adequately covering their health care expenses. This fact is documented by statistic data: $62.1 \%$ of personal bankruptcies in 2010 were caused by expenditures on health care, while $78 \%$ of those bankrupt people were insured (9). This is not a small number - in the year 2010 there were $1,538,033$ personal bankruptcies (1). Although this number is significant, it is actually undervalued, because it does not distinguish between couple bankruptcy (married couple filing for bankruptcy together) and individual bankruptcies. In total, it makes over 2 million cases.

The increased maintenance costs are not unique to insurance companies. Hospitals are forced to employ a significant amount of administrative employees handling accounts and dealing with private insurance companies. This decreases the amount of notaccepted health care bills from about $30 \%$ to $15 \%$. Due to the large amount of insurance companies and absence of a common standard, the insurance conditions for almost every patient differ, so without a specialized team the hospital would drown in paperwork.

It is important to notice that this bureaucracy does not contribute to health of the population in general or individual patients. In fact, the opposite - the situation of patients would be better if they did not have to constantly maintain control whether the health care they need will be finally paid by the insurance company or not. When companies find sufficient evidence to not cover a treatment, it is paid by the patient himself or the state. State also covers all the bills of Medicare or Medicaid.

\section{Japan}

In Japan, the health care expenditures are paid from taxes of both employees and employers. For entrepreneurs, it is based on the size of their income. Structure of the Japanese health care is relatively complex. Population can be, in this regard, split into 2 groups - employees ( $65 \%$ of the population) and unemployed people, entrepreneurs, pensioners and students (remaining 35\% 
of the population). From the insurance plan perspective, they can be divided into 5 groups:

State plan for employees covers about $30 \%$ of population, mostly employees of companies with 5-300 employees. They are covered by a special state agency with approximately 300 branches. It is financed by a special tax from nominal wage, which is about $8.2 \%$, split between the employer and employee.

Company-controlled plans cover about $25 \%$ of the population. The plans are managed by large companies (over 300 employees). In case that a company has over 3,000 employees, it usually has its own group that takes care of it. It is financed by an income tax of $5.8 \%$ to $9.5 \%$. The employee himself traditionally pays at least one half of the sum, frequently around $80 \%$ of it.

Patients insured by the Mutual Aid Association - around 10\% of population. The contribution is around $8.5 \%$ of wage.

Individual plans - around $0.1 \%$ to $0.4 \%$ of population.

State plan for the rest - about $35 \%$ of population - entrepreneurs, employees of companies with under 5 people, unemployed, pensioners, and children. For the ones who work it takes the form of another income tax, for the rest it is exclusively paid by the state.

Most health care plans in Japan are from private sector. In practice they are quasi-open, so they all offer standardized benefits and cover all types of health care. Money collected by state from various plans enters a national fund, from which pensions are paid (among other expenses). Participation of citizens in health care is therefore always capped $(12.2 \%$ of the expenditures paid from private money comes out as a result of the calculation for some categories of plans + traditional healers, i.e. acupuncture).

Participation of patients therefore never blocks the path to health care. They merely have the option to sacrifice monetary fund in return of extra services and traditional healers. An important fact to note is that in Japan $81 \%$ of hospitals and other medical facilities are privately owned. They all are, however, run as non-profit facilities. Insurance companies therefore cannot generate profit, insurance is financed by the state from payments required by law. The motive of profit is completely eradicated from health care, which makes it a non-profit sector by the law.

\section{France}

In France, we can observe a unique mixture of public and private sector. Public sector is composed of the insurance companies and state hospitals, which account for about $65 \%$ of all hospitals in the country. Public hospitals specialize in the long term care, education and research, while private and non-profit hospitals focus primarily on individual operations (private and non-profit hospitals split equally the remaining $35 \%$ of the market share). It is, however, impossible to observe any significant difference in quality between individual hospitals. That is a result of common financing rules - insurance works in the same way for all hospitals and practical doctors. The main principle of state insurance is that the state pays a percentage of the medical costs of patient's treatment, while this percentage increases with the seriousness of the illness, i.e. in case of cancer, the state pays everything. On average, the state finances $75-80 \%$ of the total costs. Rest is financed by the patient, while this part is optionally covered by private insurance, in which over $90 \%$ of the population participates. When the patient is not insured, he must pay all cost out of his pocket. Therefore, in the end the patient takes part in the costs of most treatments, frequently through the combination of private and public insurance. It is important to emphasise that an absolutely crucial principle of this setup is the principle that the more serious the illness is, the higher percentage of costs the state compensates. The system also maintains a freedom of choice to a degree - the patient may get private insurance or not and also may choose medic or hospital for treatment. That is a significantly higher degree of freedom compared to the system where practising physicians work as a gateway to specialised health care.

\section{Czech Republic}

In the Czech Republic, the public sector dominates the field of health care. Private sector secures about $16 \%$ of payments (1), which is significant to a degree but falls short of compared countries. Private finances are expended mainly through purchase of medicaments, extra care and fees. Fees are fixed payments for access to health care (visit of a doctor or emergency department, day in hospital), reducing overuse of the system. Introduction of fees was successful in decreasing system overuse, yet the system remains heavily overused in comparison to other countries. Second specific point of the Czech healthcare system is the economically different structure in terms of personal costs. While, in general, the usual pattern is that there are fewer practitioners who earn higher salaries, in the Czech Republic the trend is the opposite, there is a large amount of medical practitioners who receive relatively low salaries in comparison with other countries. Part of the reason for this phenomenon is the fact that the Czech healthcare system is gateway based. In order to reach a specialist, patient needs to visit a general physician, who would do the first examination and then decide whether to send the patient to the specialist. On one hand, this system decreases the degree of patient's freedom, on the other hand it helps the specialists and specialized hospitals to manage the overuse of care, since gatekeeping doctors filter patients who do not require the specialized care. Considering the overuse of the system, this is actually quite beneficial to all parties involved.*

\section{Costs and Performance}

So far, we have viewed the structures of systems, now it is necessary to proceed to the hard data. We are primarily interested in the structure and amount of finance, overuse of the given system and its performance. Following tables illustrate the aforementioned variables (1).

Here we can observe significant differences in the cost/performance ratio. In USA, the use of the system is very low and expenditures per capita very high. The death rate of newly born is significantly higher than in other countries and the life expectancy at birth is also lower. This is further emphasised by the amount of preventable deaths - deaths, which could have been prevented through better access to or performance of medical care. On the other hand, Japan seems to have very good results, yet there is

${ }^{*}$ Beginning on 1 January 2015, the regulatory fees (except for a regulatory fee for emergency services) were abolished in the Czech Republic 
Table 2. Health care financing in selected countries

\begin{tabular}{|l|c|c|c|c|}
\hline Finances as of $\mathbf{2 0 1 1}$ & France & Japan & USA & Czech Republic \\
\hline Share of public financing in \% & 77.8 & 82.1 & 48.8 & 83.8 \\
\hline Expenditures in dollars per capita by PPP & $3,970.3$ & $3,184.4$ & 8,175 & $1,929.2$ \\
\hline Expenditures: a percentage of GDP & 11.2 & 9.5 & 17.0 & 7.4 \\
\hline
\end{tabular}

Table 3. Health care system use factors in selected countries

\begin{tabular}{|l|c|c|c|c|}
\hline Overuse & France & Japan & USA & Czech Republic \\
\hline Active medical practitioners per 1,000 people & 3.09 & 2.21 & 2.46 & 3.64 \\
\hline Amount of hospital beds per 1,000 people & 6.37 & 13.4 & 3.05 & 6.84 \\
\hline Average amount of consultations per person per year & 6.8 & 13.1 & 4.1 & 11.1 \\
\hline
\end{tabular}

Table 4. Health care system performance indicators in selected countries

\begin{tabular}{|l|c|c|c|c|}
\hline Quality factors & France & Japan & USA & Czech Republic \\
\hline Life expectancy at birth & 82.2 & 82.5 & 78.7 & 78.0 \\
\hline Infant mortality per 1,000 births in absolute value & 3.34 & 2.17 & 5.2 & 3.7 \\
\hline Amount of preventable deaths per 100,000 people & 65.0 & 71.0 & 103.0 & 134.2 \\
\hline
\end{tabular}

one glaring issue, the system is extremely overused. The extent of actual overuse is best illustrated by the following simple calculation - 1 person makes in average 13.1 consultations with a medical practitioner per year. That is 13,100 consultations, for which there are on average 2.21 medical practitioners. One doctor therefore provides on average 22 consultations with a patient per working day. France is somewhere in the middle, aside from the amount of preventable deaths, where it has the best score and also happens to perform the best in the world. The Czech Republic has a specific position. It combines very low costs with high overuse of the system and average performance. Costs are clearly the lowest among compared countries, where expenditures per capita in dollars based on purchasing power parity (PPP) are about one quarter of the ones in USA and about a third lower than in Japan. Overuse is in a strong contrast with the costs. Usually, one would expect the system less used to have lower costs. However, that is not the case here for the overuse of the system is the highest from compared countries. The amount of medical practitioners per 1,000 people as well as the number of hospital beds is the highest among compared countries. The amount of consultations is the second highest. Results in performance parameters are competitive in comparison to other countries, infant mortality is almost in line with the top countries, while the amount of avoidable deaths is higher.

\section{DISCUSSION}

We compared the health care systems on the basis of uniformly gathered data, which are focused on health care system design, costs and performance. The systems are in fact set within the wider environment. This environment differs greatly between countries and has a significant impact on health of population and therefore statistics about the given country health care. To illustrate it, we compared homicide and obesity rates of particular countries (Fig. 2) (1).

We found little evidence supporting the hypothesis that this difference is caused by the healthcare system. Prevailing mood

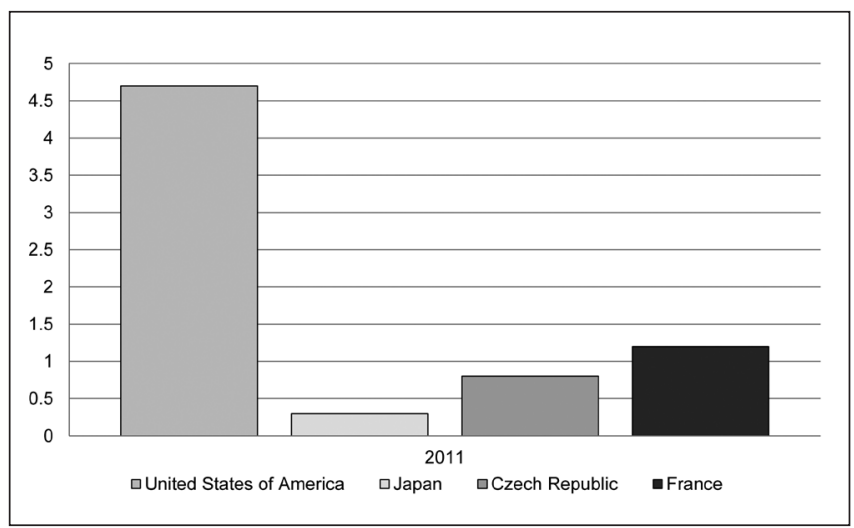

Fig. 2. Homicide rate per 100,000 people.

in society has a significant impact on the reported health parameters (1). Other factors are the background and culture of the given country. Cultural differences in approach to health can be easily observed between the countries, perhaps the best illustration would be the average obesity rates per country (Fig. 3) (10).

While obesity is not a direct measure of the health status of population, it serves as an excellent instrumental variable. Taking these extended measures into account, we arrived at the conclusion that the health status and approach to health vary between the countries, yet their relation to basic factors is unclear. On one hand we have low obesity plus high use of health care in Japan and extreme obesity rate with minimal use of health care in USA. That would support the hypothesis that high interest of patients in health to more frequent use of health care system and better health status. However, in France and the Czech Republic the relation seems to be inverse - the Czech Republic has worse health status indicators and more frequent use of the healthcare system. It is impossible to draw direct conclusion upon these observations alone, however, it provides inspiration for the future, more detailed analysis.

The other significant factor is the health policy of the given country. However, health policy is not unified across the country as there are national and local institutions which set it. Therefore, 


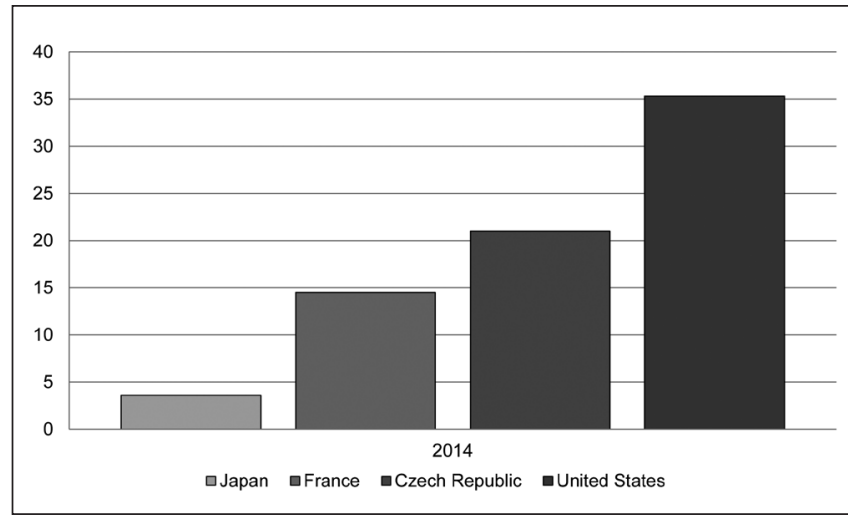

Fig. 3. Obesity rate by country.

we have derived the best estimate through the analytical description of the design and parameters of the health care system.

Lastly, there is a cultural factor of the healthcare system setups. While particular system setup may work for a given culture, it may not be applicable for a different nation. The best example is the system of Japan, where the key principle is the binding zeroprofit of private companies. Yet, the introduction of such system into a market-oriented country such as USA is unimaginable (11). It may thus be the case that given the health behaviour of a given country population and cultural background, current system may be the most feasible one.

\section{CONCLUSION}

While the increase in expenditures on health care in most countries seems to be terrifying, there are actually natural mechanisms hiding underneath. The society gets richer and therefore can use extra financial resources for health. The increase can be observed in all systems, so the structure of the system can only play a minor role in this regard. In any case, structure is the key for expenditure effective management. For this purpose we selected four countries by the role which the private sector plays in the respective healthcare systems. USA, where the private sector institutes have the main role. France, where the private sector is behind the public one in terms of the overall importance. Japan, where the private sector is bound by the law of zero profit and finally the Czech Republic, where the public sector completely dominates the field. In comparison, Japan seems to have the best performing system in terms of the performance/costs ratio since it combines great performance of the private sector with low costs of the public sector. While Japan takes the best from the both worlds, USA keep taking the worst from both - barriers to access health care caused by the private sector and weak performance of the public sector. In the end, we should mention the limitations of this paper. We did not consider the structure of population, which happens to be the best in Japan and the worst in France. We also did not take into account the (non)existence of the system of primary prevention, which could have a significant impact on analysed statistics (12). Finally, while we conducted a brief survey of health behaviour and state health policy, at the current level of analysis the evidence found was inconclusive, which provides an inspiration for the future, more detailed research.

\section{Acknowledgement}

The authors wish to thank the 1st Faculty of Medicine, Charles University in Prague and to the Institute of Economic Studies at Faculty of Social Sciences, Charles University in Prague for their support of the study by the grants GAUK 910892 and PRVOUK-P28/1LF/6.

\section{REFERENCES}

1. OECD Health statistics 2014 - frequently requested data [Internet]. OECD [cited 2014 Oct 27]. Available from: http://www.oecd.org/els/healthsystems/OECD-Health-Statistics-2014-Frequently-Requested-Data.xls.

2. Quinn J, Bencko V. Food security, public health, financial regimes and international law. In: Westra L, Soskolne CL, Spady DW, editors. Human health and ecological integrity: ethics, law and human rights. New York: Routledge; 2012. p. 107-18.

3. Hitiris T. Health care expenditure and cost containment in the G7 countries. Discussion papers in economics, no. 1999/15. York: University of York, Department of Economics and Related Sudies; 1999.

4. Total personal health care spending, by age group, calendar years, 1987, 1996, 1999, 2002, 2004 [Internet]. Baltimore: US Department of Health and Human Services, Centers for Medicare and Medicaid Services [cited 2014 Oct 27]. Available from: https://www.cms.gov/Research-StatisticsData-and-Systems/Statistics-Trends-and-Reports/NationalHealthExpendData/downloads/2004-age-tables.pdf.

5. Nolte E, McKee CM. Measuring the health of nations: updating an earlier analysis. Health Aff (Millwood). 2008 Jan-Feb;27(1):58-71.

6. Blanchflower DG. Happiness and health care coverage. Discussion paper series, no. 4450. The Institute for the Study of Labor (IZA): Bonn; 2009.

7. Buchmueller, T, Valletta, R. Health insurance costs and declining coverage. FRBSF Econ Lett. 2006 Sep 29;(25).

8. Mattoon RH. Can the states solve the health care crisis? Econ Perspect. 1992 Nov;16(6):15-27.

9. Himmelstein DU, Thorne D, Warren E, Woolhandler S. Medical bankruptcy in the United States, 2007: results of a national study. Am J Med. 2009 Aug; 122(8):741-6.

10. OECD. Obesity update. Jun 2014 [Internet]. OECD; 2014 [cited 2014 Oct 27]. Available from: http://www.oecd.org/els/health-systems/ObesityUpdate-2014.pdf.

11. Zelený T, Bencko V. The Splendours and miseries of combined healthcare financing. Prakt Lek. 2011;91(4):206-9. (In Czech.)

12. Bencko V. Primary prevention of diseases: current challenges and opportunities. Prakt Lek. 2011;91(3):127-30. (In Czech.) 